\title{
To Study Stress and Educational Adjustment among Urban and Rural School going Children
}

\author{
Seema Bajaj and Harpreet Kaur
}

\begin{abstract}
Aim: The aim of the study was to assess stress and educational adjustment among urban and rural school going children. Materials and method: Sample of 200 school going children (100 urban and 100 rural) were selected. For data collection, Academic Stress Inventory for School Students and Educational Adjustment Inventory for School Students by Seema Rani and Dr. Basant Bahadur Singh were used. Results: A significant difference exists between mean scores of the variable of stress and educational adjustment of urban and rural school going children. Conclusion: It was concluded that urban school going children are more stressful than their rural counterpart. Rural school going children have higher level of educational adjustment than their urban counterparts.
\end{abstract}

\author{
Seema Bajaj \\ Assistant Professor \\ Master Tara Singh Memorial College for Women \\ Ludhiana (Punjab) India \\ E-mail: seemabajaj74in@yahoo.co.in \\ Harpreet Kaur \\ Nursing Officer \\ Advance Trauma centre \\ Post Graduate Institute for Medical Education and \\ Research (PGIMER), Chandigarh,India \\ E-mail: Smilepreet198@gmail.com
}

\section{Key Words: Stress, Educational Adjustment, Urban and Rural}

DOI: $10.18376 / j e s p / 2020 / v 16 / 11 / 154128$

\section{Introduction}

Stress is defined as a negative emotional, cognitive, behavioral and physiological process that occurs when a person tries to adjust or deal with stressors (Bernstein et al., 2008). Academic stress is a situation that arises due to various academic factors. It is the feeling of distress in school or at home due to the numerous educational conflicts. It is the major reason behind the stress among school students. This stress challenges the student from all aspects. The students have to face several academic demands such as appearing for school examinations, showing positive progress in all subjects and fulfill other mandatory requirements. Educational adjustment is the process of adapting to the role of being a student and to the various aspects of the school environment. It is nowadays considered as a crucial point in the life of a child as the whole upcoming life would be based on this adjustment strategy. The educational adjustment among adolescents determines the nature of a person and his way of adjusting. Elgar et al., (2003) examined the stress and coping among rural and urban adolescents. Life event questionnaire and youth self- report were utilized for this. It was found that despite irregular patterns of socio-economic conditions, there was similar response by the rural and urban adolescents and there was no significant difference between findings in terms of residence area. Suailman et al., (2009) conducted a research to determine degree of stress among rural and urban school going students in Malaysia. Total 155 students appeared for their study and survey method by administering students- life stress inventory (SSI) 
was used. The results had shown that there was significant difference between stress levels of rural and urban area students. Linda et al., (2008) conducted a study to explore the effects of rurality on school-related variables and found that participation in school and non-school activities, a strength of rural schools, can play a positive role in school adjustment. Chen et al., (2019) performed a research study on 1175 students to assess the school adjustment among urban and rural migrants. Data was collected through teacher records, self-reports and school reports. It was depicted that rural area migrant students performed far well in terms of adjustment as compared to urban students.

\section{Materials and Method}

The present study was conducted on 200 children (100 urban and100 rural). The students of age 614 years were selected from a reputed private school Kharar district Mohali. In the present study Academic Stress Inventory for School Students (ASISS) developed by Seema Rani and Basant Bahadur Singh (2019) was used. The Educational Adjustment Inventory (EAI) developed by Seema Rani and Basant Bahadur Singh (2014) was used for data collection.

\section{Results and Discussion}

The variable of stress among school going urban and rural children was tested for normalcy.

Table 1. Mean, Median, Mode, Standard Deviation, Skewness and Kurtosis of scores of Urban and Rural School going Children on the variable of Stress

\begin{tabular}{|c|c|c|c|c|c|c|}
\hline Group & Mean & Median & Mode & S.D. & Skewness & Kurtosis \\
\hline Urban School going Children & 117.18 & 116.00 & 113.64 & 18.90 & 0.001 & 0.950 \\
\hline Rural School going Children & 105.20 & 107.00 & 110.60 & 17.16 & 0.003 & 0.219 \\
\hline
\end{tabular}

Table 1 show that the values of mean, median and mode of the scores of urban school going children on the variable of stress are 117.18, 116.0 and 113.64 respectively which are quite proximate to each other. The values of skewness and kurtosis in case of urban school going children are 0.001 and 0.950 respectively showing the distribution as positively skewed and platykurtic. These distortions are quite small. Therefore, the distributions can be taken as normal. The values of mean, median and mode of the scores of rural school going children on the variable of stress are 105.20, 107.00 and 110.60 respectively which are quite proximate to each other. The values of skewness and kurtosis in case of rural school going children are 0.003 and 0.219 respectively showing the distribution as positively skewed and platykurtic. But these distortions are quite small. Therefore the distributions can be taken as normal.

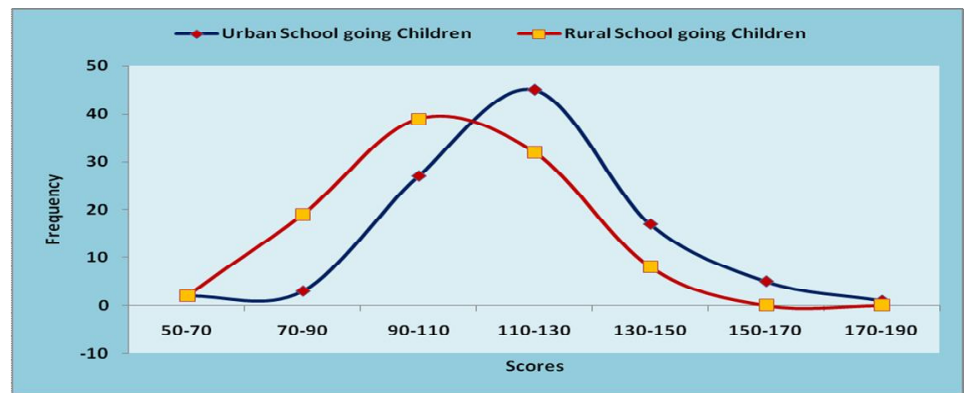

Figurer 1. Frequency Polygon of scores of Urban and Rural School going Children on the variable of Stress 
Journal of Exercise Science \& Physiotherapy Vol. 16 No. 1 (January to June) 2020

ISSN: 0973-2020 (Print) $\quad \mathrm{I}_{2} \mathrm{OR}$ Impact Factor $=6.850$

ISSN: 2454-6089 (Online)

Table 2. Difference between Mean Scores of Stress among Urban and Rural School going Children

\begin{tabular}{|c|c|c|c|c|c|c|c|}
\hline Group & Variable & $\mathbf{N}$ & M & S.D & $\mathbf{S E}_{\mathbf{M}}$ & t-ratio & Sig./Not Sig. \\
\hline Urban & \multirow[b]{2}{*}{ Stress } & 100 & 117.18 & 18.90 & 1.89 & \multirow[b]{2}{*}{4.69} & \multirow[b]{2}{*}{ Sig. at .01 level } \\
\hline Rural & & 100 & 105.20 & 17.16 & 1.72 & & \\
\hline
\end{tabular}

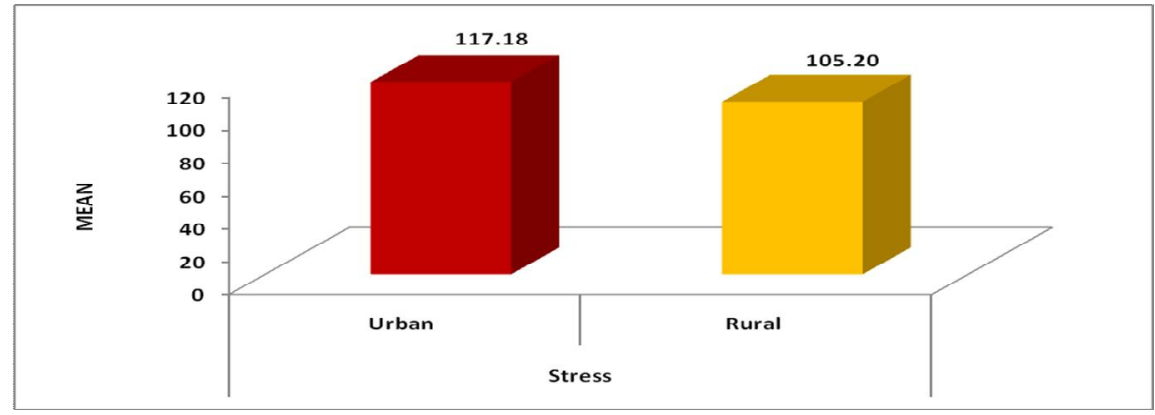

Figure 2. Difference between Mean Scores of Stress among Urban and Rural School going Children

Table 2 shows that mean scores of the variable of stress of urban and rural school going children as 117.18 and 105.20 respectively. The t-ratio is calculated as 4.69 with $d_{f}=198$ which is significant at .01 level. This revealed that a significant difference exists between mean scores of the variable of stress of urban and rural school going children. As mean score of stress of urban school going children were found to be higher than that of rural school going children, hence it may be concluded further that urban school going children are more stressful than their rural counterpart (Figure 1, Figure 2 and Table 2).

Table 3. Mean, Median, Mode, Standard Deviation, Skewness and Kurtosis of scores of Urban and Rural School going Children on the variable of Educational adjustment

\begin{tabular}{|c|c|c|c|c|c|c|}
\hline Group & Mean & Median & Mode & S.D. & Skewness & Kurtosis \\
\hline Urban School going Children & 28.22 & 28.00 & 27.56 & 3.53 & 0.948 & 0.747 \\
\hline Rural School going Children & 37.03 & 36.00 & 33.94 & 4.24 & 0.912 & 0.460 \\
\hline
\end{tabular}

The variable of educational adjustment among urban and rural school going children was tested for normalcy. Table 3 shows that the values of mean, median and mode of the scores of urban school 


\section{Journal of Exercise Science \& Physiotherapy Vol. 16 No. 1 (January to June) 2020 \\ ISSN: 0973-2020 (Print) $\quad I_{2}$ OR Impact Factor $=6.850 \quad$ ISSN: 2454-6089 (Online)}

going children on the variable of educational adjustment as 28.22, 28.00 and 27.56 respectively which are quite proximate to each other. The values of skewness and kurtosis in case of urban school going children are 0.948 and 0.747 respectively showing the distribution as positively skewed and platykurtic. But these distortions are quite small. Therefore the distributions can be taken as normal. The values of mean, median and mode of the scores of rural school going children on the variable of educational adjustment as 37.03, 36.00 and 33.94 respectively which are quite proximate to each other. The values of skewness and kurtosis in case of rural school going children are 0.912 and 0.460 respectively showing the distribution as positively skewed and platykurtic. But these distortions are quite small. Therefore the distributions can be taken as normal.

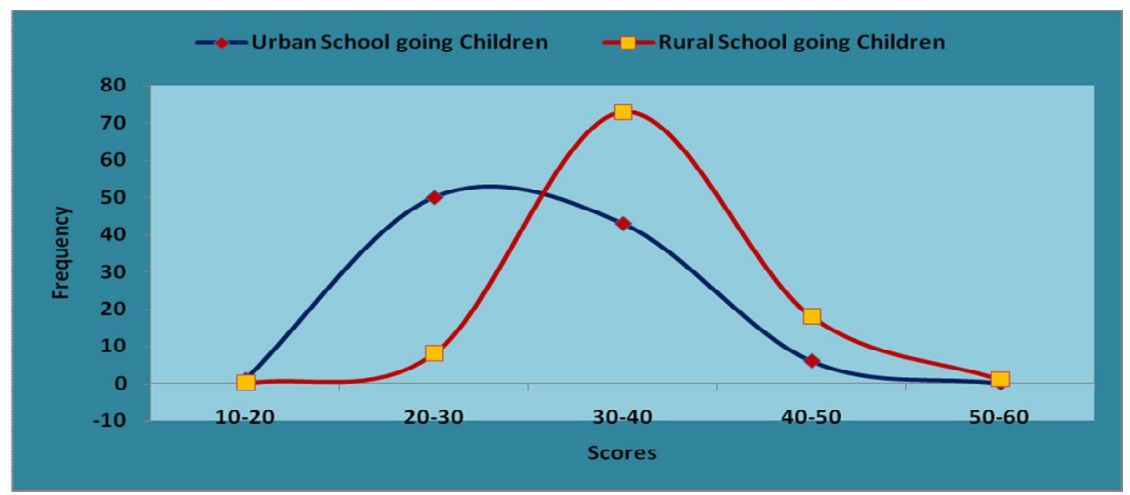

Figure 3. Frequency Polygon of scores of Urban and Rural School going Children on the variable of Educational Adjustment

Table 4. Difference between Mean Scores of Educational Adjustment among Urban and Rural School going

\begin{tabular}{|c|c|c|c|c|c|c|c|}
\hline Group & Variable & $\mathbf{N}$ & M & S.D & $\mathbf{S E}_{\mathbf{M}}$ & t-ratio & Sig./Not Sig. \\
\hline Urban & \multirow[b]{2}{*}{ Educational Adjustment } & 100 & 28.22 & 3.53 & 0.35 & \multirow{2}{*}{15.98} & \multirow{2}{*}{ Sig. at .01 level } \\
\hline Rural & & 100 & 37.03 & 4.24 & 0.42 & & \\
\hline
\end{tabular}

Table 4 revealed that the mean scores of the variable of educational adjustment of urban and rural school going children as 28.22 and 37.03 respectively. The t-ratio is calculated as 15.98 with $\mathrm{d}_{\mathrm{f}}$ $=198$ which is significant at .01 level. This revealed that a significant difference exists between mean scores of the variable of educational adjustment of urban and rural school going children. As mean score of educational adjustment of rural school going children was found to be higher than urban children, hence it may be concluded further that rural school going children have high level of educational adjustment than their urban counterparts (Figure 3, Figure 4, Table 3and Table 4). 


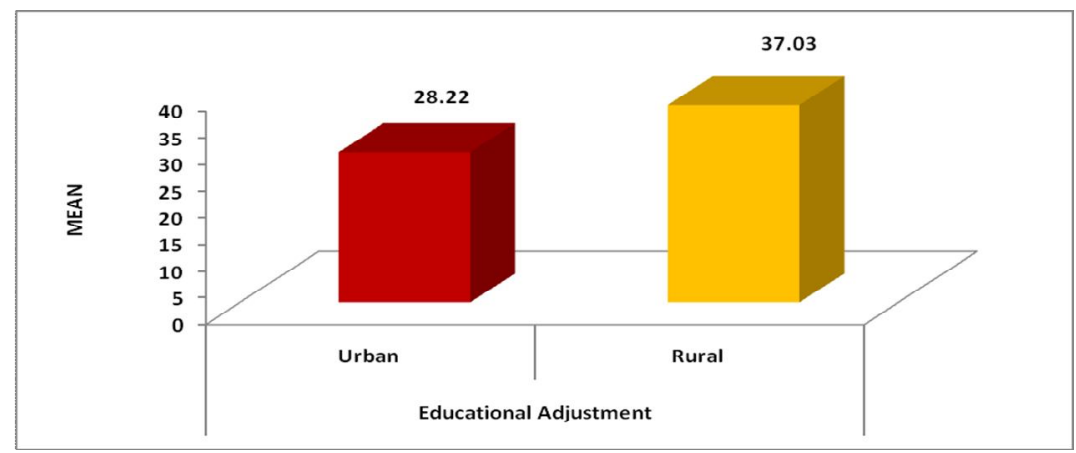

\section{Figure 4. Difference between Mean Scores of Educational Adjustment among Urban and Rural School going Children}

\section{Conclusion}

It was concluded that a significant difference exists between mean scores of the variable of stress of urban and rural school going children. As mean score of stress of urban school going children were found to be higher than that of rural school going children, hence it may be concluded that urban school going children are more stressful than their rural counterpart. Moreover, a significant difference exists between mean scores of the variable of educational adjustment of urban and rural school going children. As mean score of educational adjustment of rural school going children was found to be higher than urban children, hence it may be concluded further that rural school going children have higher level of educational adjustment than their urban counterpart.

\section{References}

Bernstein, D. A., Penner, L. A., Stewart, A. C., \& Roy, E. J. 2008.Psychology ( $8^{\text {th }}$ edition). Houghton Mifflin Company, Boston, New York.

Chen, X., Li, Dan., Xu, Xinpei., Liu, J., Fu, R., Cui, L., Liu, S.2019. School adjustment of children from rural migrant families in urban China. Journal of School Psychology. Vol.72, February, pp. 14-28.

Elgar, F., Groves, R. 2003. Stress, coping and behavioral problems among rural and urban adolescents. Journal of adolescence. November 2003, DOI: 10.1016/S0140-1971 (03)00057-5.26(5):577-88.

Linda R. Stanley, Maria Leonora G. Comello, Ruth W. Edwards \& Beverly S. Marquart .2008. School Adjustment in Rural and Urban Communities: Do Students from "Timbuktu" Differ from Their "City Slicker" Peers? Journal of Youth and Adolescence Volume 37, pages 225-238.

Seema Rani, and Basant Bahadur Singh.2014.Educational Adjustment Inventory (EAI). National Psychological Corporation, Agra, India

Seema Rani, and Basant Bahadur Singh.2019. Academic Stress Inventory for School Students (ASISS). National Psychological Corporation, Agra, India

Sulaiman, Tajularipinand Hassan, Aminuddin and M.Sapian, Vizata and Abdullah, Saifuddin Kumar. 2009. The level of stress among students in urban and rural secondary schools in Malaysia. European Journal of Social Sciences, 10(2),pp179-184. 